\title{
Association of Sick Sinus Syndrome with Hyperinsulinemia and Insulin Resistance in Patients with Non-Insulin-Dependent Diabetes Mellitus: Report of Four Cases
}

\author{
Taro Wasada, Kozo Katsumori, Sumiko Hasumi, Hiroshi Kasanuki*, Hiroko ArII, \\ Akiko Saeki, Hiroyuki Kuroki, Setsu SaIto and Yasue OMORI
}

\begin{abstract}
We report four non-insulin-dependent diabetic (NIDDM) patients accompanied by a unique combination of sick sinus syndrome (SSS) and hyperinsulinemia of unknown etiology. SSS of all four cases was due to sinus arrest in association with paroxysmal atrial fibrillation (RubensteinIII). Of special interest is that one patient showed a high prevalence of SSS and NIDDM among her close relatives. Hyperinsulinemia of moderate degree was seen at fasting state or after carbohydrate ingestion in the absence of obesity. The resistance to the action of insulin on glucose metabolism which was evaluated in three patients by the euglycemic hyperinsulinemic clamp study was found to be comparable to the lowest quartile level for common NIDDM patients. Because insulin is a physiological regulator of cell-membrane $\mathrm{Na}^{+} / \mathrm{K}^{+}$-ATPase, we speculate that malfunction of the sinus node automaticity may be caused by chronic exposure to hyperinsulinemia secondary to insulin resistance in these NIDDM patients.
\end{abstract}

(Internal Medicine 34: 1174-1177, 1995)

Key words: $\mathrm{Na}^{+} / \mathrm{K}^{+}$-ATPase, tyrosine kinase activity, euglycemic hyperinsulinemic clamp method, pacemaker implantation

\section{Introduction}

Sick sinus syndrome (SSS), or sinoatrial dysfunction, usually occurs following many cardiac or systemic diseases. However, it also occurs without underlying diseases, and in such cases the pathophysiological cause is unknown (1-3). During the long-term follow-up of a patient with non-insulin-dependent diabetes mellitus (NIDDM) who had been uniquely accompanied by both SSS and hyperinsulinemia of unknown etiology, we encountered three similar cases. To date, no association between SSS and hyperinsulinemia has been reported in the literature, but it seems unlikely that they co-exist by chance alone, because one of our patients has a family history of a high prevalence of SSS and diabetes either in combination or alone. In the present report, we describe the clinical profiles of four NIDDM patients accompanied by SSS and hyperinsulinemia secondary to insulin resistance, and propose possible mechanisms underlying the association of these apparently unrelated disorders.

\section{Case Report}

\section{Case 1: H.S., 70-year-old female}

The patient had a history of rheumatic fever at the age of 27 years old. This caused mitral stenosis and tricuspid regurgitation. At the age of 50 years old, she had episodes of paroxysmal atrial fibrillation. She underwent the commissurotomy of the mitral valve along with tricuspid valve plasty at the age of 51 years. Four years later, faintness began. Electrocardiogram (ECG) monitoring disclosed sinus arrest following a burst of paroxysmal atrial fibrillation (Rubenstein-III) (2). A pacemaker device was implanted, at which time NIDDM and hyperinsulinemia were discovered (Table 1-case 1). The patient's maternal aunt is an insulin-treated diabetic patient with heart disease since adolescence. The patient's height was 153.0 $\mathrm{cm}$ and weight was $51.5 \mathrm{~kg}$ (BMI 22.0). There was no history of obesity or hypertension, and she showed no diabetic retinopathy, nephropathy or neuropathy. As shown in Table 1 (case 1), hyperinsulinemia persisted for over 15 years, although its degree gradually decreased, probably because of pancreatic beta-cell exhaustion. Anti-insulin antibodies and anti-insulin

From the Diabetes Center, *Department of Cardiology, The Heart Institute of Japan, Tokyo Women's Medical College, Tokyo Received for publication November 15, 1994; Accepted for publication September 5, 1995

Reprint requests should be addressed to Dr. Taro Wasada, Diabetes Center, Tokyo Women's Medical College, 8-1 Kawada-cho, Shinjuku-ku, Tokyo 162 
Table 1. Plasma Concentrations of Glucose (BS), Insulin (IRI) and C-peptide Immunoreactivity (CPR), and 24-Hour Urinary Excretion of CPR

\begin{tabular}{|c|c|c|c|c|c|c|c|c|c|c|c|c|c|c|}
\hline & & \multicolumn{4}{|c|}{$\begin{array}{c}\text { BS } \\
(\mathrm{mg} / \mathrm{dl})\end{array}$} & \multicolumn{4}{|c|}{$\begin{array}{c}\text { IR } \\
(\mu \mathrm{U} / \mathrm{ml})\end{array}$} & \multicolumn{4}{|c|}{$\begin{array}{c}\text { CPR } \\
(\mathrm{ng} / \mathrm{ml})\end{array}$} & \multirow[t]{2}{*}{$\begin{array}{r}\text { U-CPR } \\
(\mu \mathrm{g} / \text { day })\end{array}$} \\
\hline & $\min$ & 0 & 30 & 60 & 120 & 0 & 30 & 60 & 120 & 0 & 30 & 60 & 120 & \\
\hline \multirow[t]{6}{*}{ Case 1} & $\begin{array}{l}\text { 100g OGTT } \\
(1979.12 .20)\end{array}$ & 87 & 181 & 214 & 176 & 44 & 166 & 385 & 423 & & & & & \\
\hline & $\begin{array}{l}\text { 75g OGTT } \\
\quad(1986.9 .24)\end{array}$ & 84 & 175 & 223 & 210 & 24 & - & 166 & 313 & 4.6 & - & 11.2 & 19.7 & \\
\hline & $\begin{array}{l}\text { MTT } \\
\quad(1987.11 .4)\end{array}$ & 126 & - & 207 & 184 & 22 & - & 134 & 220 & 4.8 & - & 11.7 & 14.9 & 229.3 \\
\hline & $\begin{array}{l}\text { MTT } \\
\quad(1988.5 .31)\end{array}$ & 166 & - & 260 & 274 & 13 & - & 67 & 141 & & & & & 214.4 \\
\hline & $\begin{array}{l}\text { MTT } \\
\quad(1992.10 .14)\end{array}$ & 171 & 223 & 262 & 271 & 21 & 58 & 109 & 130 & 6.4 & 8.1 & 17.0 & 21.0 & 248.2 \\
\hline & $\begin{array}{l}\text { MTT } \\
\quad(1993.3 .8)\end{array}$ & 149 & 216 & 258 & 312 & 27 & 74 & 170 & 260 & 7.4 & 9.1 & 18.6 & 19.0 & 271.3 \\
\hline \multirow[t]{2}{*}{ Case 2} & $\begin{array}{l}\text { 75g OGTT } \\
(1989.4 .19)\end{array}$ & 130 & 238 & 318 & 350 & 28 & 52 & 118 & 148 & & & & & \\
\hline & $\begin{array}{l}\text { MTT } \\
\quad(1993.10 .14)\end{array}$ & 284 & - & 461 & 521 & 14 & - & 42 & 89 & & & & & \\
\hline \multirow[t]{3}{*}{ Case 3} & $\begin{array}{l}\text { 75g OGTT } \\
(1982.3 .8)\end{array}$ & 97 & 185 & 169 & 122 & 26 & - & 60 & 131 & & & & & \\
\hline & $\begin{array}{l}\text { 75g OGTT } \\
\quad(1989.4 .14)\end{array}$ & 149 & 185 & 206 & 237 & 33 & 41 & 47 & 109 & & & & & 84.0 \\
\hline & $\begin{array}{l}\text { MTT } \\
\quad(1994.5 .23)\end{array}$ & 266 & - & 463 & 563 & 16 & - & 28 & 58 & & & & & \\
\hline \multirow[t]{2}{*}{ Case 4} & $\begin{array}{l}\text { 75g OGTT } \\
\quad(1993.6 .21)\end{array}$ & 149 & 249 & 305 & 329 & 21 & 39 & 58 & 84 & & & & & 175.6 \\
\hline & $\begin{array}{l}\text { 75g OGTT } \\
\quad(1994.6 .16)\end{array}$ & 142 & 225 & 269 & 254 & 39 & 65 & 64 & 60 & 7.3 & 8.7 & 10.7 & 10.0 & \\
\hline
\end{tabular}

OGTT: oral glucose tolerance test, MTT: meal tolerance test, U-CPR: urinary excretion of C-peptide immunoreactivity. Normal range for $\mathrm{U}_{-} \mathrm{CPR}, 30-84 \mu \mathrm{g} / \mathrm{day}$.

Table 2. Insulin-Stimulated Glucose Disposal Rate (GDR) and Insulin Receptor Tyrosine Kinase Activity of Red Blood Cells

\begin{tabular}{|c|c|c|c|}
\hline Case & $\begin{array}{c}\text { GDR } \\
(\mathrm{mg} / \mathrm{kg} / \mathrm{min})\end{array}$ & $\begin{array}{l}\text { Iaximal stimulation } \\
\text { by insulin* } \\
\text { (\% of basal) }\end{array}$ & $\begin{array}{c}\mathrm{ED}_{50} \\
\left(\times 10^{-10} \mathrm{M}\right)\end{array}$ \\
\hline 1 & 1.44 & 162 & 6.0 \\
\hline \multicolumn{4}{|l|}{2} \\
\hline 3 & 3.40 & & \\
\hline 4 & 2.12 & 209 & 8.0 \\
\hline NIDDM & $3.57 \pm 0.14(n=238)$ & $175 \pm 30(n=70)$ & $8.6 \pm 0.36(n=70)$ \\
\hline Control & $6.53 \pm 0.37(n=25)$ & & \\
\hline
\end{tabular}

GDR was determined by the euglycemic clamp method (insulin infusion rate: $1.12 \mathrm{mU} / \mathrm{kg} / \mathrm{min}$, clamp level of plasma glucose: $80 \mathrm{mg} /$ dl). $* 10^{-7} \mathrm{M}$ of insulin, mean \pm SD. receptor antibodies were not found. Her diabetes was successfully treated with diet alone initially, but subsequently with sulfonylurea drug. At the age of 66, she suffered a cerebral embolism. The insulin resistance was assessed by the euglycemic hyperinsulinemic clamp method (4). The glucose disposal rate (GDR), a measure of resistance to insulin-stimulated glucose uptake in the whole-body, was markedly reduced (Table 2). However, autophosphorylation of insulin receptor of patient's red blood cells, an index of an early event of insulin action, measured by the enzyme-linked immunosorbent assay (5) was normal (Table 2).

\section{Case 2: C.A., 69-year-old female}

The patient was apparently in good health until the age of 33, when paroxysmal atrial fibrillation appeared. At the age of 55 years old, the episodes of faintness began. Holter's ECG revealed paroxysmal sinus arrest (Rubenstein-III). Under the 
diagnosis of Adams-Stokes syndrome due to SSS, a pacemaker device was introduced successfully. Six years later, she was admitted to our hospital to have the pacemaker generator replaced, at which time NIDDM and hyperinsulinemia were discovered (Table 1-case 2). Her family history was negative for diabetes and cardiac disease. The patient's height was $143.0 \mathrm{~cm}$ and weight was $46.5 \mathrm{~kg}$ (BMI 22.7). There was no history of obesity or hypertension. Diabetic complications were not present and serum biochemical tests were normal except for dyslipidemia (triglyceride $347 \mathrm{mg} / \mathrm{dl}$ and HDL-cholesterol 20 $\mathrm{mg} / \mathrm{dl}$ ). She refused euglycemic hyperinsulinemic clamp study.

\section{Case 3: I.I., 73-year-old female}

The patient had been treated for hypertension for approximately 30 years. At the age of 50 years old, paroxysmal atrial fibrillation occurred. She experienced episodes of faintness since age 60. Holter ECG disclosed short-runs of premature atrial contraction and sinus arrest for 3-4 seconds (RubensteinIII); a pacemaker device was successfully implanted, at which time hyperinsulinemia in the presence of almost normal glucose tolerance was found. At the age of 70 , an oral glucose tolerance test (OGTT) disclosed diabetes and hyperinsulinemia (Table 1 -case 3). Family history included one dead sister who had diabetes and syncopal attacks. The patient's height was 150.0 $\mathrm{cm}$ and weight was $51.0 \mathrm{~kg}$ (BMI 22.7). There was no history of obesity. No diabetic retinopathy and nephropathy were present, but moderate intermittent claudication due to arteriosclerosis obliterance was noted. The value of GDR was approximated at the average value of common NIDDM patients, which is lower than that in healthy subjects (Table 2).

\section{Case 4: N.U., 59-year-old female}

The patient had been in good health until 41 years old, when syncopal episodes occurred. An ECG showed sinus bradycardia (25-35/min) with occasional sinus arrest lasting maximal 10 seconds (Rubenstein-II). A pacemaker device was implanted with no recurrence of episode thereafter. Eighteen years later, paroxysmal atrial fibrillation was superimposed (Rubenstein-III), then she was admitted to our hospital for renewal of the pacemaker device, at which time diabetes and hyperinsulinemia were found (Table 1-case 4). Interestingly, her family history revealed that three of her 5 siblings were diabetic and three had SSS (two had both NIDDM and SSS). One brother died due to cerebral embolism at age 19. Her mother, two maternal uncles, and three maternal cousins were suspected of having SSS, and two other maternal cousins had pacemakers implanted for definite SSS. No OGTT was ever performed for these relatives with proven or suspected SSS. Patient's height was $144.0 \mathrm{~cm}$ and weight was $45.5 \mathrm{~kg}$ (BMI 21.9). There was no history of obesity or hypertension. No diabetic retinopathy or neuropathy were noted but she was dyslipidemic (total cholesterol $249 \mathrm{mg} / \mathrm{dl}$, HDL-cholesterol 31 $\mathrm{mg} / \mathrm{dl}$ and triglyceride $309 \mathrm{mg} / \mathrm{dl}$ ). Her diabetes was maintained at a stable state $\left(\mathrm{HbA}_{1 \mathrm{c}}\right.$ under $\left.6 \%\right)$ on diet alone. The value of GDR was low, but insulin receptor tyrosine kinase activity of her red blood cells was normal (Table 2).

\section{Discussion}

SSS is most often found in the elderly, thereby it is thought to be related to arteriosclerotic or hypertensive heart disease, or other specific diseases such as senile amyloidosis. However, in most cases of SSS a specific cause cannot be identified (1-3). It is also not known whether SSS is more common among diabetic patients. The electrophysiological mechanism which causes SSS is far from clear. The present cases have several common features with respect to SSS: 1) SSS was due to sinus arrest rather than sinoatrial block. 2) Paroxysmal atrial fibrillation preceded the occurrence of sinus arrest in three of the four cases, though one case showed the reverse order. 3) Sinus arrest occurred around 55-60 years of age except in one case, in whom it developed earlier, probably because of a strong genetic predisposition. All patients had a moderate hyperinsulinemia in the fasting state or during glucose (or meal) loading tests. The three patients studied showed a substantial resistance to the insulin action on glucose metabolism: The estimated GDR was $1.44,2.12$ and $3.40 \mathrm{mg} / \mathrm{kg} / \mathrm{min}$. These values corresponded to the lowest quartile level for 135 NIDDM patients evaluated using the identical euglycemic clamp method in our laboratory (6). Thus, hyperinsulinemia and insulin resistance of this extent is relatively uncommon in Japanese non-obese NIDDM patients. In addition, one of our patients was extraordinary because her family history showed a high prevalence of SSS and NIDDM. Therefore, we are tempted to suppose that the association of these disorders did not occur by chance alone. With respect to the temporal relationship between these disorders, the three patients developed SSS first, and then NIDDM and hyperinsulinemia were found later, but in one patient (case 1), NIDDM and hyperinsulinemia were documented almost concomitantly with the occurrence of SSS. Considering that diabetes usually occurs several years before its clinical recognition, it is conceivable that the onset of the two diseases could be close. Our speculations concerning the mechanism for the association of these disorders are as follows: it is well known that insulin stimulates the cell-membrane $\mathrm{Na}^{+} / \mathrm{K}^{+}$-ATPase (79 ), which is vital to all cells and serves a variety of crucial functions. The activity of $\mathrm{Na}^{+} / \mathrm{K}^{+}$-ATPase of nerve and muscle cells is of particular importance because these cells generate the action potential and facilitate its conduction. When one mole of ATP is hydrolyzed, its free energy is used for extrusion of three $\mathrm{Na}$ ions outside the cell and for entry of two $\mathrm{K}$ ions into the cell, and thus the $\mathrm{Na}^{+} / \mathrm{K}^{+}$-ATPase is electrogenic. This Na, K-pump primarily works to restore the resting potential during recovery from membrane depolarization resulting from the rapid movement of $\mathrm{Na}$ ions into the cells. Thus, the $\mathrm{Na}^{+} / \mathrm{K}^{+}$-ATPase activity is a key factor in maintaining a cyclic generation of active potential in excitable cells. Insulin regulates this pump activity, therefore it is considered as one of the physiological modulators of heart rate. If the electrogenic $\mathrm{Na}^{+} / \mathrm{K}^{+}$-ATPase is chronically exposed to hyperinsulinemia, the sinus node cells might remain hyperpolarized via a persistent decrease in the intracellular $\mathrm{Na}^{+}$concentration. Indeed, it was shown that the plasma membrane of skeletal muscle cells can be hyperpolar- 
ized when incubated with physiologic concentration of insulin in vitro (10). Recently, insulin was shown to enhance the expression of mRNA encoding the alpha- 2 isoform of $\mathrm{Na}^{+} / \mathrm{K}^{+}$ATPase in vascular smooth muscle cells (11). Consequently, insulin plays an important role in regulation of $\mathrm{Na}^{+} / \mathrm{K}^{+}$-ATPase through enhancing gene expression of some components of the enzyme as well as up-regulating its activity. In clinical practice, it is well known that the reappearance of sinus node rhythm after overdrive suppression with high frequency electrical pacing of the atrium is characteristically delayed in SSS (12), suggesting increased activity of the Na,K-pump of the sinus node. Furthermore, the observation in laboratory animals and in patients that the sinus rate can be slowed and AV nodal conduction can be depressed by administration of adenosine $(13,14)$, which is a stimulus for $\mathrm{Na}^{+} / \mathrm{K}^{+}$-ATPase, seems to corroborate our proposition. In other situations, the frequent occurrence of atrial fibrillation or flutter in the thyrotoxic state may be related to the increased $\mathrm{Na}^{+} / \mathrm{K}^{+}$-ATPase activity, because thyroid hormone (T3) has been shown to stimulate $\mathrm{Na}^{+} / \mathrm{K}^{+}$-ATPase and also to up-regulate its gene expression in responsive tissues $(7,15,16)$. This may be supported by the observation that these arrhythmias are easily reversed by administration of digitalis drugs, potent inhibitors of $\mathrm{Na}^{+} / \mathrm{K}^{+}$-ATPase. Taking these findings into account, the enhancement of sodium pump activity or its gene expression by chronic hyperinsulinemia could explain the derangement of sinus node automaticity. In this context, it is unclear whether the $\mathrm{Na}^{+} / \mathrm{K}^{+}$-ATPase is also resistant to insulin, because the cellular transport of glucose and potassium ions is shown to be separately regulated by insulin $(17,18)$. Therefore, the resistance to insulin-mediated glucose disposal does not indicate resistance to insulin stimulation of $\mathrm{Na}^{+} / \mathrm{K}^{+}$-ATPase. In addition, insulin activation of tyrosine kinase of red blood cell insulin receptors was normal in two patients studied, indicating the intactness of this critical step of signal transduction by insulin. Because SSS is not necessarily seen in even more severe insulin resistant subjects, the $\mathrm{Na}^{+} / \mathrm{K}^{+}$-ATPase hypothesis may be explicable for a subset of patients with SSS. Furthermore, some genetic linkage appears to exist between these two disorders, as suggested by the family history of case 4 showing a high incidence of SSS and possibly insulinresistant NIDDM in the same pedigree. To further explore the relationship between these disorders, the accumulation of data regarding such cases is clearly needed.

\section{References}

1) Ferrer MI. The sick sinus syndrome. Circulation 47: 635, 1973.

2) Rubenstein JJ, Schulman CL, Yurchak PM, DeSanctis RW. Clinical spectrum of the sick sinus syndrome. Circulation 46: 5, 1972.

3) Rosen KM, Loeb HS, Sinno MZ, Rahimtoola SH, Gunnar RM. Cardiac conduction in patients with symptomatic sinus node disease. Circulation 43: $836,1971$.

4) Wasada T, Kuroki H, Arii H, et al. Relationship between insulin resistance and risk factors for cardiovascular disease in Japanese NIDDM patients. Diabetes Res Clin Pract 25: 191, 1994.

5) Hagino H, Shii K, Matsuba H, et al. Enzyme-linked immunosorbent assay method for human autophosphorylated insulin receptor, applicability to insulin-resistant states. Diabetes 43: 274, 1994.

6) Wasada $\mathrm{T}$, Kuroki $\mathrm{H}$, Arii $\mathrm{H}$, et al. Insulin resistance and clustering of coronary artery disease risk factors in non-insulin-dependent diabetes mellitus. J Jpn Diab Soc 37: 177, 1994 (in Japanese).

7) Gick GG, Ismail-Beigi F, Edelman IS. Hormonal regulation of $\mathrm{Na}, \mathrm{K}$ ATPase: overview. Prog Clin Biol Res 268B: 277, 1988.

8) Gelehrter TD, Shreve PD, Dilworth VM. Insulin regulation of Na/K pump activity in rat hepatoma cells. Diabetes 33: 428, 1984.

9) Resh MD, Nemenoff RA, Guidotti G. Insulin stimulation of $\left(\mathrm{Na}^{+} / \mathrm{K}^{+}\right)$adenosine triphosphatase-dependent $86 \mathrm{RB}^{+}$uptake in rat adipocytes. J Biol Chem 255: 10938, 1980.

10) Zierler KL, Rogus EM. Rapid hyperpolarization of rat skeletal muscle induced by insulin. Biochim Biophys Acta 640: 687, 1981.

11) Tirupattur PR, Ram JL, Standley PR, Sowers JR. Regulation of $\mathrm{Na}^{+}, \mathrm{K}^{+}$ATPase gene expression by insulin in vascular smooth muscle cells. Am J Hypertens 6: 626, 1993.

12) Mandel W, Hayakawa H, Danzig R, Marcus HS. Evaluation of sinoatrial node function in man by overdrive suppression. Circulation 44: 59, 1971.

13) James TN, Bear ES, Frink RJ, Urthaler F. Pharmacologic production of atrioventricular block with and without initial bundle branch block. J Pharmacol Exp Ther 179: 338, 1971.

14) Favale S, DiBiase M, Rizzo U, Belardinelli L, Rizzon P. Effect of adenosine and adenosine-5-triphosphate on atrioventricular conduction in patients. J Am Coll Cardiol 5: 1212, 1985.

15) Ismail-Beigi F, Edelman IS. Mechanism of thyroid calorigenesis: role of active sodium transport. Proc Natl Acad Sci 67: 1071, 1970.

16) Philipson $\mathrm{KD}$, Edelman IS. Characteristics of thyroid-stimulated $\mathrm{Na}^{+}$ $\mathrm{K}^{+}$-ATPase of rat heart. Am J Physiol 232: C202, 1977.

17) Ferrannini E, Taddei $S$, Santoro $D$, et al. Independent stimulation of glucose metabolism and $\mathrm{Na}^{+}-\mathrm{K}^{+}$exchange by insulin in the human forearm. Am J Physiol 255: E953, 1988.

18) Cohen P, Barzilai N, Lerman A, Havel H, Szylman P, Karnich E. Insulin effects on glucose and potassium metabolism in vivo: evidence for selective insulin resistance in humans. J Clin Endocrinol Metab 73: 564, 1991. 